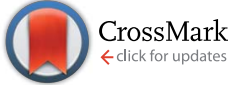

Cite this: J. Mater. Chem. A, 2015, 3, 19884

Received 7th July 2015

Accepted 25th August 2015

DOI: $10.1039 / \mathrm{c} 5 \mathrm{ta0} 5075 \mathrm{~h}$

www.rsc.org/MaterialsA

\title{
Hematite iron oxide nanorod patterning inside COK-12 mesochannels as an efficient visible light photocatalyst $\uparrow$
}

\author{
L. H. Wee, ${ }^{\star a}$ M. Meledina, ${ }^{b}$ S. Turner, ${ }^{b}$ K. Custers, ${ }^{a}$ S. Kerkhofs, ${ }^{a}$ G. van Tendeloo ${ }^{b}$ \\ and J. A. Martens ${ }^{a}$
}

\begin{abstract}
The uniform dispersion of functional oxide nanoparticles inside ordered mesoporous silica to tailor optical, electronic, and magnetic properties for biomedical and environmental applications is a scientific challenge. Herein, we demonstrate for the very first time the morphological effect of platelet-driven confined growth of hematite iron oxide $\left(\alpha-\mathrm{Fe}_{2} \mathrm{O}_{3}\right)$ nanorods inside the mesochannels of ordered mesoporous silica COK-12 material denoted as $\alpha-\mathrm{Fe}_{2} \mathrm{O}_{3} \mathrm{CCOK}-12$. The inclusion of the $\alpha-\mathrm{Fe}_{2} \mathrm{O}_{3}$ nanorods in $\mathrm{COK}-12$ particles is studied in detail using high-angle annular dark field scanning transmission electron microscopy (HAADFSTEM), energy-dispersive X-ray (EDX) spectroscopy and electron tomography. High resolution imaging and EDX spectroscopy provide information about the particle size, shape and crystal phase of the loaded $\alpha-\mathrm{Fe}_{2} \mathrm{O}_{3}$ material, while electron tomography provides detailed information on the spreading of the nanorods throughout the COK-12 host in three-dimension. This nanocomposite material, having a semiconductor band gap energy of $2.50 \mathrm{eV}$ according to diffuse reflectance spectroscopy, demonstrates an improved visible light photocatalytic degradation activity with rhodamine 6G and 1-adamantanol model compounds.
\end{abstract}

\section{Introduction}

Ordered mesoporous silica materials have received considerable attention over the past decades, owing to their high surface area and uniform pore size. ${ }^{1-3}$ Thanks to enriched supramolecular templating and sol-gel chemistry, ${ }^{4}$ precise control over pore size,,$^{5-11}$ wall thickness ${ }^{12,13}$ and morphology ${ }^{14-22}$ of the ordered mesoporous silica have been achieved. The ordered mesopores can act as a nano-host ${ }^{23,24}$ for the construction of multifunctional materials through the encapsulation of functional nanosized guest compounds such as proteins, ${ }^{25}$ fluorescent dyes, ${ }^{26}$ metallic and metal-oxide nanoparticles ${ }^{27-29}$ for emerging advanced applications such as bio-imaging and drug delivery, ${ }^{30-32}$ magnetics, ${ }^{33}$ electronics ${ }^{34,35}$ and (photo)catalysis. ${ }^{36-40}$ Mesoporous silica materials loaded with transition metal oxide nanocrystals are particularly interesting due to their exceptional physicochemical properties. ${ }^{41}$ The mesopores of

${ }^{a}$ Centre for Surface Chemistry and Catalysis, KU Leuven, Celestijnenlaan 200f, B3001, Heverlee, Belgium. E-mail: likhong.wee@biw.kuleuven.be; Fax: +32 16321998; Tel: $+3216376748$

${ }^{b}$ Electron Microscopy for Materials Science, University of Antwerp, Groenenborgerlaan 171, B2020, Antwerp, Belgium

$\uparrow$ Electronic supplementary information (ESI) available: Physicochemical properties of COK-12 and $\alpha-\mathrm{Fe}_{2} \mathrm{O}_{3} @ \mathrm{COK}-12$ (Table S1), XRD pattern of $\alpha-\mathrm{Fe}_{2} \mathrm{O}_{3} @ \mathrm{COK}-12$ (Fig. S1) and a movie showing the three-dimensional visualization of the $\alpha-\mathrm{Fe}_{2} \mathrm{O}_{3}$ distribution over a COK-12 host (Movie S1). See DOI: $10.1039 / \mathrm{c} 5$ ta05075h silica material serving as a confined nest for the growth of iron oxide nanoparticles have been reported to possess a clear superparamagnetic effect ${ }^{42-45}$ and (photo)catalytic activity. ${ }^{46-48}$ The size regime and morphology of nanostructured materials, where the collective behavior of bulk materials emerges from the discrete nature of molecular properties is significantly crucial for improving their overall physicochemical properties. ${ }^{\mathbf{9}}$ For instance, the high-aspect-ratio of nanorods/nanowires would provide sufficient thickness of the absorber layer to achieve excellent optical absorption while simultaneously minimizing collection lengths for excited carriers in a direction normal to the light absorption. In addition, semiconductor nanorod/nanowire arrays have been proven to show a higher optical absorption property due to its lower reflective losses compared to planar semiconductors. ${ }^{49}$

Electron tomography is a TEM technique that allows to reconstruct the three-dimensional (3D) structure of a given material from a series of two-dimensional projections/images, taken at regular tilt intervals. ${ }^{50}$ The development of electron tomography over the past years has allowed material scientists to gain further insight into the morphology, composition and physical properties of materials in three dimensions. ${ }^{\text {51-68 }}$ For example, using discrete electron tomography, the 3D microstructure and mesopore visualization of zeotile-4, a complex mesoporous material, has been achieved. ${ }^{69}$ Electron tomography has also proven to be a powerful tool for the analysis of nanoparticles supported within silica and other porous 
materials like metal-organic framework and zeolites, providing important information on the distribution and preferential location of catalysts nanoparticles. ${ }^{70}$ In the field of catalysis, visualization and analysis of the three-dimensional structure and chemistry of a functional material by electron tomography is of significantly importance not only to gain a full picture of the microstructure at the nanometer level but also to allow further understanding and optimization of the material performance. ${ }^{71}$ For example, qualitative and quantitative analysis of noble metals in zeolite Y catalyst by electron tomography has helped to provide scientific insights into the importance of metal nanoparticle loading and particle size in macroscale catalyst performance. ${ }^{72}$

Although several synthetic approaches for the impregnation of metal oxide nanocrystals into the mesochannels of the mesoporous silica materials have been reported, e.g. direct synthesis, ${ }^{73}$ templating ${ }^{74}$ or wetting/impregnation, ${ }^{75-77}$ precise and systematic incorporation of iron oxide nanorods inside the mesochannel of ordered mesoporous silica has not been documented to date. In this paper, we show fascinating example of morphological effect of platelet-driven homogeneous and confined growth of iron oxide nanorods inside the short mesochannels of COK-12 as active and recyclable visible light photocatalysts. The three-dimensional visualization of the functional iron oxide nanorod patterning along the mesostructures of COK-12 at its nanoscale dimension was revealed by electron tomography.

\section{Experimental}

\section{Materials}

Pluronic triblock copolymer P123 (BASF Corporation), citric acid monohydrate ( $\geq 99 \%$, Sigma-Aldrich), trisodium citrate dihydrate ( $\geq 99 \%$, Sigma-Aldrich), sodium silicate solution (extra pure, Merck), iron(III) nitrate nanohydrate $(\geq 99.5 \%$, Sigma-Aldrich), absolute ethanol (analytical grade, Fisher Scientific), Milli-Q water (18.2 $\mathrm{M} \Omega \mathrm{cm})$.

\section{Synthesis}

COK-12 was synthesized according to the recipe reported by Jammaer et al. ${ }^{21,22}$ For a typical synthesis, $4 \mathrm{~g}$ of Pluronic triblock copolymer P123 was dissolved in $107.5 \mathrm{~g}$ of distilled water and added $3.6 \mathrm{~g}$ of citric acid monohydrate and $2.5 \mathrm{~g}$ of trisodium citrate dehydrate. The solution was stirred for $24 \mathrm{~h}$ at room temperature. Another solution containing $10.4 \mathrm{~g}$ of sodium silicate in $30 \mathrm{~g}$ of distilled water was prepared and added to the surfactant solution. The mixed solution was stirred for $10 \mathrm{~min}$ and left static at room temperature for $24 \mathrm{~h}$. The solid was filtered and washed with distilled water and dried at room temperature. The material was calcined at $550{ }^{\circ} \mathrm{C}$ for $8 \mathrm{~h}$ with a heating rate of $1{ }^{\circ} \mathrm{C} \mathrm{min}^{-1}$. In preliminary experiments, we varied the concentration of the iron precursor and we experienced that $0.1 \mathrm{M}$ concentration was an optimum to maximize the deposition of iron in the pores. For the synthesis of $\alpha-\mathrm{Fe}_{2}$ $\mathrm{O}_{3}$ @COK-12 material, $200 \mathrm{mg}$ of calcined COK-12 was added to $0.1 \mathrm{M}$ of iron(III) nitrate nanohydrate ethanol solution and stirred for $10 \mathrm{~min}$. The suspension was left static at room temperature for $24 \mathrm{~h}$. The material was recovered via centrifugation at $4000 \mathrm{rpm}$ and the ethanol solution was discarded. The sediment was dried at room temperature and followed by calcinations at $550{ }^{\circ} \mathrm{C}\left(1{ }^{\circ} \mathrm{C} \min ^{-1}\right)$ for $8 \mathrm{~h}$.

\section{Characterization}

COK-12 and $\alpha-\mathrm{Fe}_{2} \mathrm{O}_{3} @ \mathrm{COK}-12$ materials were characterized by a scanning electron microscopy (SEM, Philips XL-30 FEG equipped with a tungsten filament), $\mathrm{N}_{2}$ adsorption (Micromeritics Tristar 3000), solid state UV-Vis NIR spectroscopy (Cary Series Varian spectrophotometer), and SAXS performed using a SAXSess $\mathrm{mc}^{2}$ (Anton Paar GmbH, Graz, Austria) instrument. The sample was loaded into a vacuum-tight rotor cell and measured using line-collimated $\mathrm{Cu} \mathrm{K} \alpha$ radiation and an image plate detector. Measurements were performed for $5 \mathrm{~min}$ at room temperature $\left(25{ }^{\circ} \mathrm{C}\right)$. Diffraction patterns were normalized to incident beam intensity. Background subtraction and correction for instrumental broadening was performed using the SAXSquant software. The scattering of the empty rotor cell was subtracted as background. HAADF-STEM imaging was performed on a FEI Titan "cubed" microscope, operated at $120 \mathrm{kV}$ acceleration voltage. The convergence semi-angle used was 21 mrad, the inner ADF detection angle was 85 mrad. EDX mapping and electron tomography were carried out on a FEI Tecnai Osiris microscope, operated at $200 \mathrm{kV}$ and equipped with a wide solid angle "super-X" EDX detector. The convergence semi-angle used was $10 \mathrm{mrad}$, the inner ADF detection angle was 68 mrad. Images for tomographic reconstruction were acquired from +64 to -64 degrees, taking an image every 2 degrees. The SIRT reconstruction using 50 iterations was performed using the FEI Inspect3D software, visualization was carried out using the Amira software package.

\section{Photocatalysis}

The photocatalytic tests were carried out in a Luzchem photoreactor equipped with rotating sample carousel and 14 cool white fluorescent light tubes (Sylvania, 8 watts, $12^{\prime \prime}$ ), 8 of which were positioned at the top and 3 on both sideways of the reactor compartment. Air-saturated aqueous solutions $(5 \mathrm{~mL})$ of rhodamine $6 \mathrm{G}$ or 1-adamantanol (200 ppm) to which $10 \mathrm{mg}$ of $\alpha-\mathrm{Fe}_{2} \mathrm{O}_{3} @ \mathrm{COK}-12$ or pure $\alpha-\mathrm{Fe}_{2} \mathrm{O}_{3}$ nanopowder (Sigma-Aldrich, $<50 \mathrm{~nm}$ particle size) was added into the closed Pyrex test tubes (10 mL volume), each provided with a magnetic stirring bar. To exclude any possible influence of the temperature on the degradation of the organic compound, the temperature in the reactor was set at $35{ }^{\circ} \mathrm{C}$ by using a thermostat. Prior to visible light illumination, the suspension was strongly magnetically stirred for $1 \mathrm{~h}$ in the dark for achieving adsorption/desorption equilibrium. The visible light irradiation was turned on for $3 \mathrm{~h}$. After reaction, the catalyst was separated from the aqueous solution by centrifugation. The percentage of rhodamine 6G and 1-adamantanol degradation were determined by a UV-Vis spectrophotometry (TECAN Infinite M200 PRO, with Tecan i-control software) and gas chromatography (Shimadzu 
GC-2014, 60 m long HP-1 capillary column (Agilent) equipped with an flame ionization detector (FID) detector), respectively.

\section{Results and discussion}

Surface modification and gas phase impregnation technique to confine the growth of $\mathrm{PbS}$ nanocrystals ${ }^{78}$ and NiO nanoparticle ${ }^{64}$ respectively inside the channels of SBA-15 has previously been reported. COK-12 (Centrum voor Oppervlatechemie en Katalyse No. 12) with hexagonally arrays (space group of $P 6 \mathrm{~m}$ symmetry) of short mesochannels was synthesized via room temperature spontaneous precipitation of sodium silicate in citrate/citric acid buffered triblock copolymer solution at quasineutral pH. Herein, we demonstrate the use of COK-12 with its readily accessible short mesochannels for systematic patterned growth of iron oxide nanorods across the platelets without the need of surface modification. Fig. 1a shows the SEM images of COK-12 hexagonal thin platelets. The average width and thickness of the platelets are $1 \mu \mathrm{m}$ and 200-300 nm, respectively. The morphology of COK-12 was retained after calcination at $550{ }^{\circ} \mathrm{C}$ in air in order to remove the occluded surfactant micelles as shown in Fig. $1 \mathrm{~b}$.

The hexagonal ordering of the calcined COK-12 materials was studied by small-angle X-ray scattering (SAXS). The SAXS pattern shown in Fig. 2a exhibits four distinct diffraction peaks in the low-angle region which can be indexed to the (100), (110), (200) and (210) planes of 2D hexagonal mesostructured for space group $P 6 m$ symmetry, indicating that the ordered mesostructure is stable and well retained after calcination process. The $d$-spacing value of COK-12 is $9.28 \mathrm{~nm}$ which corresponds to a unit cell parameter $a=10.7 \mathrm{~nm}$ (see Table S1 $\dagger$ ). The $d$-spacings for the $\alpha-\mathrm{Fe}_{2} \mathrm{O}_{3} @ \mathrm{COK}-12$ do not shift when compared to the parent COK-12 material, suggesting that the mesoporous structure remains intact after the incorporation of iron oxide nanorods. The $\mathrm{N}_{2}$ adsorption-desorption isotherms of parent COK-12 and $\alpha-\mathrm{Fe}_{2} \mathrm{O}_{3} @$ COK-12 materials are shown in Fig. $2 b$. Both the materials exhibit a type IV isotherm with a H1 hysteresis loop, typical characteristic of mesoporous materials with hexagonal arrays of parallel cylindrical mesopores run in the short direction through the platelets. ${ }^{22}$ The calculated Barrett-Joyner-Halenda $(\mathrm{BJH})$ pore size, pore volume and Brunauer-Emmett-Teller (BET) surface area of COK-12 and

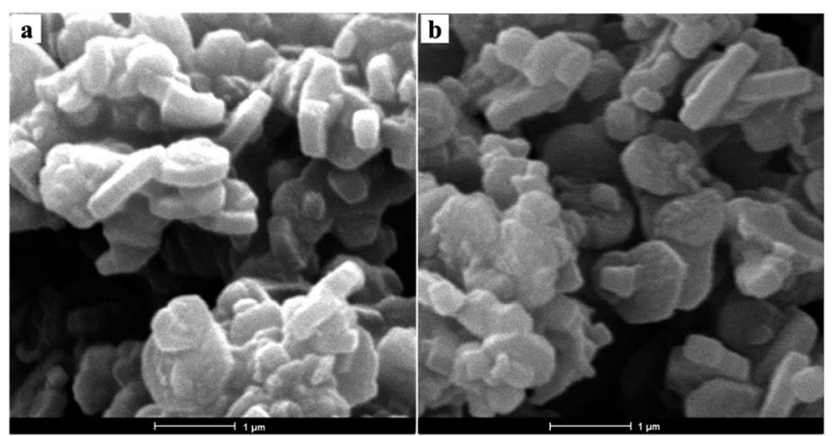

Fig. 1 SEM images of (a) as-synthesized COK-12 and (b) calcined COK-12.
$\alpha-\mathrm{Fe}_{2} \mathrm{O}_{3} @ \mathrm{COK}-12$ are summarized in Table $\mathrm{S} 1 \mathrm{\dagger}^{\dagger}$ The pore volume of the $\alpha-\mathrm{Fe}_{2} \mathrm{O}_{3} @ \mathrm{COK}-12$ material is smaller than the parent COK-12 which suggests that the nanoparticles are located inside the mesopores rather than on the external surface. $\alpha-\mathrm{Fe}_{2} \mathrm{O}_{3} @ \mathrm{COK}-12$ has high specific surface area, indicating that the pores are not fully blocked by the iron oxide. The pore accessibility will be beneficial for application in liquid phase photocatalysis, which will be demonstrated later in this study (vide infra).

The Fe content of $\alpha-\mathrm{Fe}_{2} \mathrm{O}_{3} @ \mathrm{COK}-12$ according to elemental analysis was $3.5 \mathrm{wt} \%$. The wide-angle XRD pattern of $\alpha-\mathrm{Fe}_{2}$ $\mathrm{O}_{3} @$ @OK-12 shows no diffraction (see Fig. S1 $\dagger$ ), suggesting nano-dimensions for the iron oxide particles. In order to gain insight into the morphology and structure, scanning
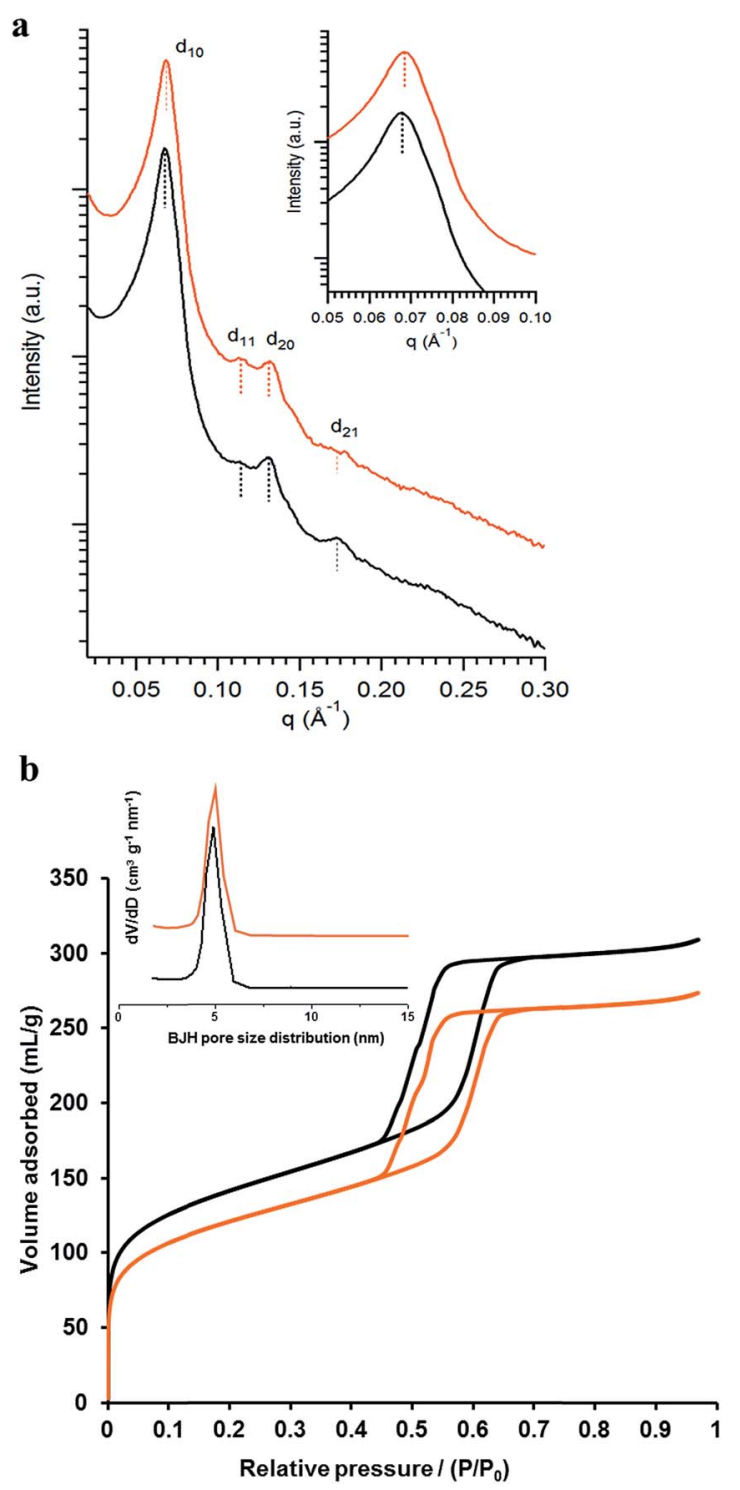

Fig. 2 (a) SAXS patterns of calcined $\mathrm{COK}-12$ (black) and $\alpha-\mathrm{Fe}_{2} \mathrm{O}_{3} \mathrm{a}$ COK-12 (orange). The insert shows the corresponding enlarged view of the $\mathrm{d}_{10}$ peak. (b) $\mathrm{N}_{2}$ adsorption-desorption isotherms of COK-12 (black) and (b) $\alpha-\mathrm{Fe}_{2} \mathrm{O}_{3}(\mathrm{CCOK}-12$ (orange). The insert shows the corresponding $\mathrm{BJH}$ pore size distribution. 
transmission microscopy was used. In Fig. 3, Z-contrast highangle annular dark field STEM (HAADF-STEM) images of the $\alpha$ $\mathrm{Fe}_{2} \mathrm{O}_{3} @ \mathrm{COK}-12$ sample are displayed. The image in Fig. 3a, taken along the COK-12 pore direction, remarkably reveals the presence of well-distributed iron oxide nanorods, appearing as bright-contrast features in the image. Well-ordered mesopores arranged in a 2D hexagonal $P 6 \mathrm{~m}$ structure are clearly aligned along the COK-12 thin platelets, as evidenced by the Fourier transform pattern (Fig. 3a, insert). Intriguingly, individual iron oxide nanorods confined to a single mesopore are clearly visible in the magnified HAADF-STEM image in Fig. 3b. The mean pore diameter and wall thickness of COK-12 estimated from the HAADF-STEM images were $(5.0 \pm 0.3 \mathrm{~nm})$ and $(4.3 \pm 0.3 \mathrm{~nm})$, respectively. These values match perfectly with the pore size obtained via nitrogen sorption and unit cell parameter derived from SAXS measurement. The HAADF-STEM image of $\alpha-\mathrm{Fe}_{2}$ $\mathrm{O}_{3}$ @COK-12 taken perpendicular to the pore direction reveals that the iron oxide nanorods actually demonstrate an interestingly self-oriented growth fashion along the mesopore direction, as indicated by the arrows in Fig. 3c (insert). In Fig. 3d, a high resolution HAADF-STEM image is displayed of an individual nanoparticle in the material. The crystalline phase of the iron oxide can be correctly indexed as hematite $\left(\alpha-\mathrm{Fe}_{2} \mathrm{O}_{3}\right)$. The typical width of the $\alpha-\mathrm{Fe}_{2} \mathrm{O}_{3}$ nanorods is approximately $5 \mathrm{~nm}$, which fits inside the mesopores having a similar diameter estimated using $\mathrm{N}_{2}$ adsorption (Fig. 2b, insert). The $\alpha-\mathrm{Fe}_{2} \mathrm{O}_{3}$ nanorods are elongated in the COK-12 channel direction.
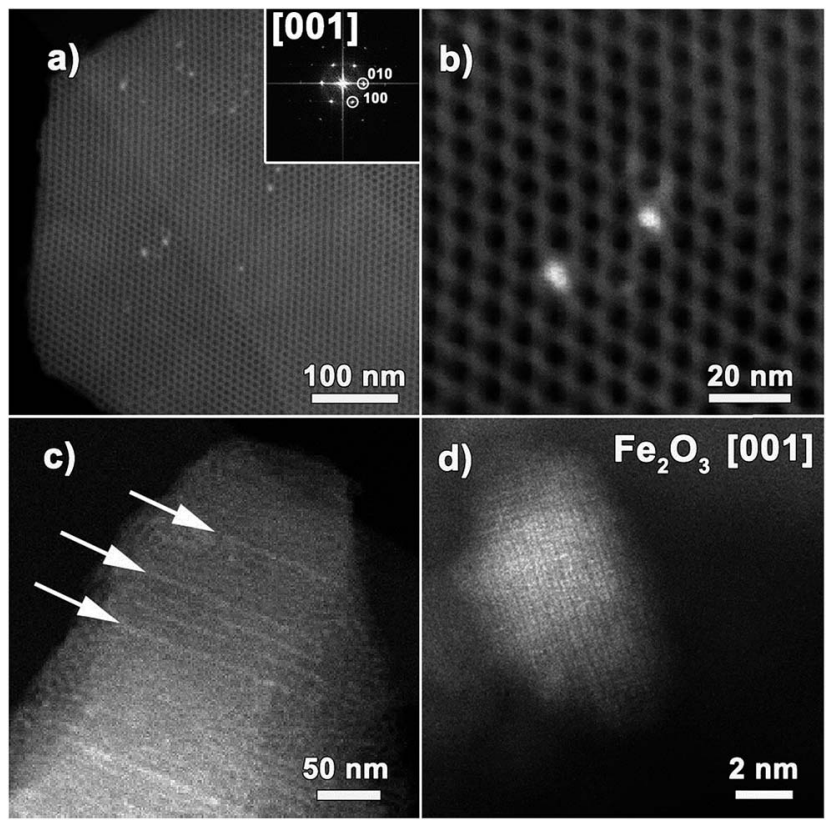

d)

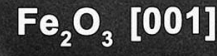

Fig. 3 HAADF-STEM characterization of $\alpha$-Fe $\mathrm{O}_{3} \mathrm{OCOK}-12$ (a) HAADF-STEM image of $\alpha-\mathrm{Fe}_{2} \mathrm{O}_{3} \mathrm{aCOK}-12$ taken along the pore direction with inset Fourier transform pattern. (b) Magnified region from (a), showing the particles are confined to single pores. (c) HAADFSTEM image of $\alpha-\mathrm{Fe}_{2} \mathrm{O}_{3} \mathrm{CCOK}-12$ taken perpendicular to the pore direction and showing bright elongated structures following the pore direction (indicated by arrows). (d) High resolution image of a single $\mathrm{Fe}_{2} \mathrm{O}_{3}$ nanoparticle, evidencing the $\alpha-\mathrm{Fe}_{2} \mathrm{O}_{3}$ crystal structure.
The distribution of iron and silicon in the COK-12 platelets was investigated using EDX analysis and mapping (Fig. 4b and e). The distribution of Fe is consistent with the HAADF-STEM analysis, indicating that all elongated structures contain $\mathrm{Fe}$, and that the nanorods are distributed uniformly over the COK-12 platelets. Individual iron oxide nanorods formed inside the mesochannels of COK-12 (Fig. 4b, green spots) can be located precisely.

Due to the two-dimensional nature of the electron micrographs, it is impossible to ascertain the three-dimensional location of these $\alpha-\mathrm{Fe}_{2} \mathrm{O}_{3}$ nanoparticles. Thus, in order to confirm the location of these nanorods in COK-12, electron tomography was applied. By combining HAADF-STEM projected images and an iterative SIRT $^{79}$ tomographic reconstruction, a three dimensional representation of the hybrid material was obtained (Fig. 4c and f). A one-dimensional self-assembly of the crystalline $\alpha-\mathrm{Fe}_{2} \mathrm{O}_{3}$ nanorods was observed, as shown in Fig. $4 \mathrm{f}$. The close packing of $\alpha-\mathrm{Fe}_{2} \mathrm{O}_{3}$ nanorods in the channels of COK12 has resulted in the formation of an interesting $\alpha-\mathrm{Fe}_{2} \mathrm{O}_{3}$ nanorod morphology (Fig. 4f). The length of the nanorods varies from approximately 5 up to several tens of nanometers. A threedimensional visualization of the $\alpha-\mathrm{Fe}_{2} \mathrm{O}_{3}$ distribution over the COK-12 host material as well as the mesostructures of the synthesized COK-12 viewed at different pore directions can be clearly seen in Fig. 5 and a short movie as presented in the ESI (see Movie $\mathrm{S} 1 \dagger$ ).

The optical properties of the $\alpha-\mathrm{Fe}_{2} \mathrm{O}_{3} @ \mathrm{COK}-12$ material were investigated by a solid-state UV-Vis diffuse reflectance spectroscopy (Fig. 6a). The narrow maximum absorption band at 290-320 nm (Fig. 6a, orange curve) indicates the uniform diameter of the $\alpha-\mathrm{Fe}_{2} \mathrm{O}_{3}$ nanorods formed inside the mesopores, which is in full agreement with the HAADF-STEM imaging and electron tomography results. Additionally, a broad band ranging from 415-700 $\mathrm{nm}$ in the visible light region was also observed, attributed to the ligand field transition or the $\mathrm{d}-\mathrm{d}$ transitions, the ligand to metal charge transfer (LMCT) transitions, and the pair excitations resulting from the simultaneous excitations of magnetically coupled two neighboring $\mathrm{Fe}^{3+}$ cations. As expected, no absorption band was noted for the parent COK-12 material (Fig. 6a, black curve). The bandgap value of iron oxide was determined from a Tauc plot, presenting the square root of the product of the absorption coefficient and the photon energy $(F(R) h \nu)^{1 / 2}$ versus photon energy as depicted in Fig. 6b. Extrapolation of the straight line to the photon energy axis yielded a semiconductor band gap of $2.5 \mathrm{eV}$ (Fig. 6b). This value is slightly higher when compared to the reported value of $2.2 \mathrm{eV}$ for bulk $\alpha-\mathrm{Fe}_{2} \mathrm{O}_{3}$ material, suggesting a quantum confinement effect. ${ }^{80}$

Visible light is effectively an inexhaustible source of energy. Visible light photocatalysis can be performed by using essentially any source of white light, including the easily available sunlight. Thus, the development of visible-light-active photocatalysts for energy conversion and environmental remediation applications, has been enormously investigated in the recent years. Crystalline iron oxide nanoparticles exhibit excellent photocatalytic properties. Taking into account of their attractive band gap, low production cost, abundance on earth, and the 

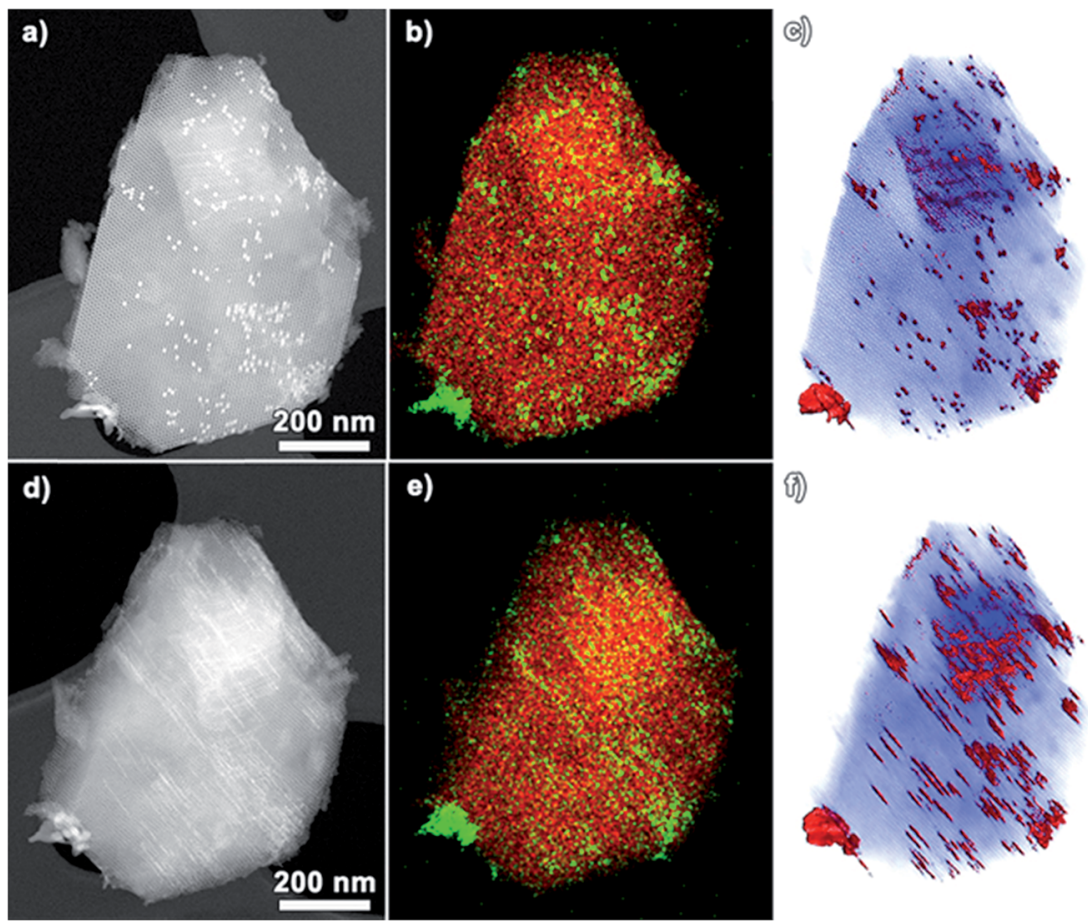

Fig. 4 EDX mapping and electron tomography of $\alpha-\mathrm{Fe}_{2} \mathrm{O}_{3} \mathrm{aCOK}-12$ (a) HAADF-STEM image of $\alpha-\mathrm{Fe}_{2} \mathrm{O}_{3} \mathrm{aCOK}-12$ taken along the pore direction (b) corresponding EDX elemental color map, with Fe in green and Si in red. (c) HAADF-STEM tomography reconstruction viewed along the pore direction. (d) HAADF-STEM image of $\alpha-\mathrm{Fe}_{2} \mathrm{O}_{3} \mathrm{OCOK}-12$ taken nearly perpendicular to the pore direction (e) corresponding EDX elemental color map, with Fe in green and $\mathrm{Si}$ in red. (f) HAADF-STEM tomography reconstruction viewed along the same direction.

chemical stability in an aqueous environment, they are promising catalysts for visible light photocatalysis. ${ }^{81-83}$ The observed strong and broad absorption band of $\alpha-\mathrm{Fe}_{2} \mathrm{O}_{3} @ \mathrm{COK}-12$ in the visible light region inspired us to evaluate its photocatalytic activity for the photodegradation of model molecules. A dye molecule rhodamine $6 \mathrm{G}$ and a mimic of off-flavor compounds in water, 1-adamantanol ${ }^{84}$ were selected for this purpose.

The photocatalytic activity of $\alpha-\mathrm{Fe}_{2} \mathrm{O}_{3} @$ @COK-12 powder was evaluated for rhodamine $6 \mathrm{G}$ and 1-adamantanol degradation under visible light illumination and compared to the commercial $\mathrm{Fe}_{2} \mathrm{O}_{3}$ nanopowder as a reference catalyst. Photocatalytic experiments were performed by adding $10 \mathrm{mg}$ of $\alpha-\mathrm{Fe}_{2} \mathrm{O}_{3} @$ @COK-12 into $5 \mathrm{~mL}$ of $200 \mathrm{ppm}$ rhodamine 6G or 1-adamantanol aqueous solutions. In order to discriminate rhodamine 6G adsorption from photodegradation, dark tests were performed prior to illumination. The suspension was magnetically stirred for $1 \mathrm{~h}$ in the dark in order to achieve adsorption/desorption equilibrium. The adsorption and photodegradation kinetic curves for rhodamine $6 \mathrm{G}$ and 1-adamantanol over $\alpha-\mathrm{Fe}_{2} \mathrm{O}_{3} @ \mathrm{COK}-12$ and $\alpha-\mathrm{Fe}_{2} \mathrm{O}_{3}$ reference catalyst a)

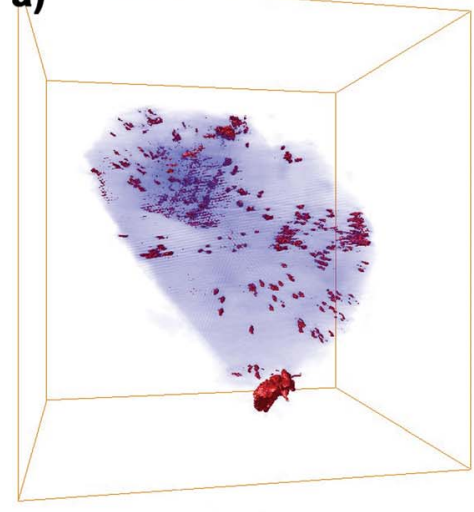

b)

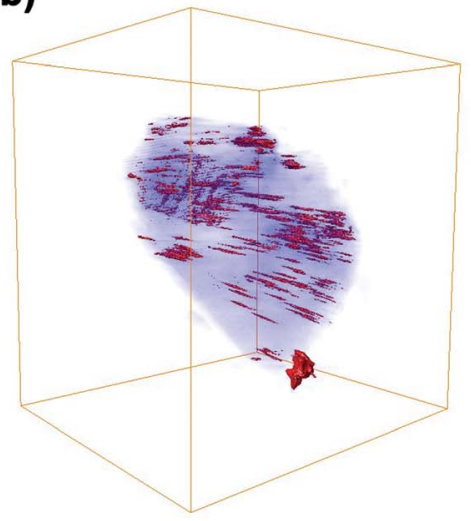

c)

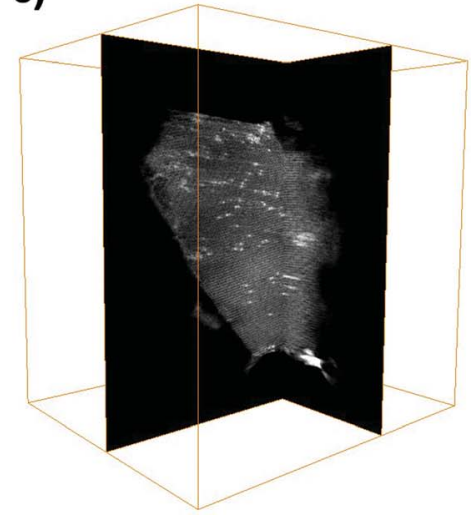

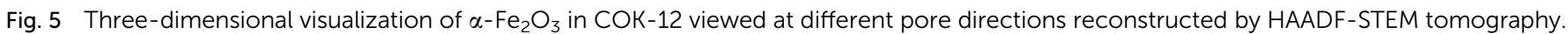

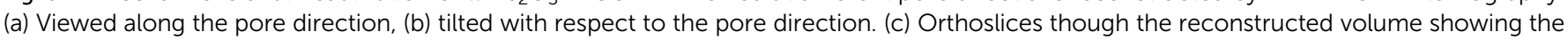
elongated $\alpha-\mathrm{Fe}_{2} \mathrm{O}_{3}$ nanorods aligned along the pores. 

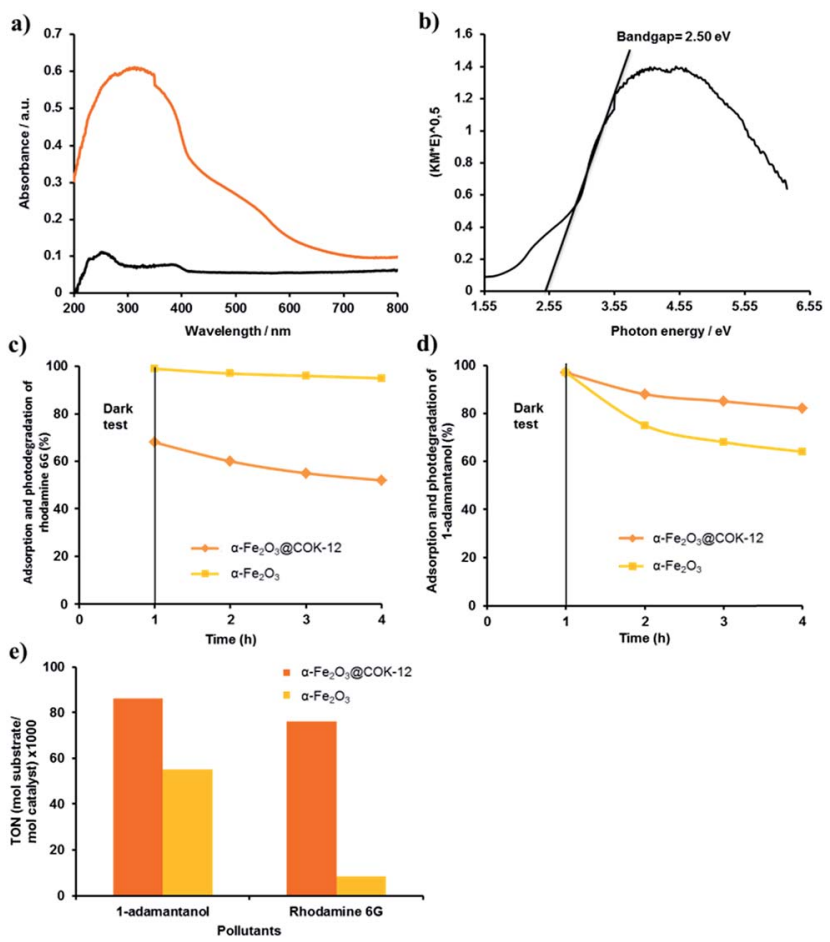

Fig. 6 (a) Solid-state UV-Vis absorption spectra of COK-12 (black curve) and $\alpha-\mathrm{Fe}_{2} \mathrm{O}_{3} @ \mathrm{CCOK}-12$ (orange curve). (b) Tauc plot of $(F(R)$ $h \nu)^{1 / 2}$ versus $h \nu$ for $\alpha-\mathrm{Fe}_{2} \mathrm{O}_{3} \mathrm{aCOK}-12$. Adsorption and photodegradation kinetic curves of (c) rhodamine 6G and (d) 1-adamantanol under visible light illumination over $\alpha-\mathrm{Fe}_{2} \mathrm{O}_{3} \mathrm{aCOK}-12$ versus commercial $\mathrm{Fe}_{2} \mathrm{O}_{3}$ catalyst. Conditions: $10 \mathrm{mg}$ of $\alpha-\mathrm{Fe}_{2} \mathrm{O}_{3} \mathrm{aCOK}-12$ or $2 \mathrm{mg}$ of $\alpha-\mathrm{Fe}_{2} \mathrm{O}_{3}$ catalyst in $5 \mathrm{~mL}$ of an aqueous solution of rhodamine $6 \mathrm{G}$ or 1-adamantanol (200 ppm) at $35^{\circ} \mathrm{C}$. (e) Turnover number (TON) of the $\alpha-\mathrm{Fe}_{2} \mathrm{O}_{3} \mathrm{QCOK}-12$ in comparison to the commercial $\alpha-\mathrm{Fe}_{2} \mathrm{O}_{3}$ reference nanocatalyst in the photodegradation of rhodamine $6 \mathrm{G}$ and 1-adamantanol. TON $=\mathrm{mol}$ of substrate degraded $/ \mathrm{mol}$ of $\alpha-\mathrm{Fe}_{2} \mathrm{O}_{3}$. The mol of substrate degraded is calculated by subtracting the mol of substrate adsorbed during the test for $1 \mathrm{~h}$ in the dark from the mol of substrate degraded at the end of the photocatalytic test.

are presented in Fig. $6 \mathrm{c}$ and d, respectively. The dark test showed that $32 \%$ of rhodamine $6 \mathrm{G}$ was adsorbed by $\alpha-\mathrm{Fe}_{2}$ $\mathrm{O}_{3}$ @COK-12 (Fig. 6c). The overall conversion of $48 \%$ after $3 \mathrm{~h}$ illumination corresponded to $16 \%$ of rhodamine $6 \mathrm{G}$ photodegradation by $\alpha-\mathrm{Fe}_{2} \mathrm{O}_{3} @ \mathrm{COK}-12$. Similarly, 15\% 1-adamantanol was photodegraded by $\alpha-\mathrm{Fe}_{2} \mathrm{O}_{3} @ \mathrm{COK}-12$ catalyst (Fig. 6d). Under similar experimental conditions, the parent COK-12 material contributed no photocatalytic activity. The estimated photodegradation rates of rhodamine $6 \mathrm{G}$ and 1-adamantanol over $\alpha-\mathrm{Fe}_{2} \mathrm{O}_{3} @ \mathrm{COK}-12$ were $1.5 \times 10^{-2} \mathrm{mg}_{\text {rhodamine 6G }}$ $\mathrm{mg}^{-1} \alpha-\mathrm{Fe}_{2} \mathrm{O}_{3} @$ COK-12 $\mathrm{h}^{-1}$ and $1.7 \times 10^{-2} \mathrm{mg}_{1 \text {-adamantanol }}$ $\mathrm{mg}^{-1} \alpha-\mathrm{Fe}_{2} \mathrm{O}_{3} @$ @OK-12 $\mathrm{h}^{-1}$, respectively which were much higher than the reference $\alpha-\mathrm{Fe}_{2} \mathrm{O}_{3}$ catalyst $\left(8.3 \times 10^{-3} \mathrm{mg}_{\text {rhodamine } 6 \mathrm{G}}\right.$ $\mathrm{mg}^{-1} \alpha-\mathrm{Fe}_{2} \mathrm{O}_{3} \mathrm{~h}^{-1}$ and $\left.5 \times 10^{-3} \mathrm{mg}_{1 \text {-adamantanol }} \mathrm{mg}^{-1} \alpha-\mathrm{Fe}_{2} \mathrm{O}_{3} \mathrm{~h}^{-1}\right)$. In order to evaluate the reactivity of $\alpha-\mathrm{Fe}_{2} \mathrm{O}_{3} @ \mathrm{COK}-12$ in comparison to commercial $\alpha-\mathrm{Fe}_{2} \mathrm{O}_{3}$ nanoparticles quantitatively, turnover number (TON), defined as mol of substrate degraded per mol of $\alpha-\mathrm{Fe}_{2} \mathrm{O}_{3}$ was also determined (Fig. 6e). The concentration of photodegraded substrate was calculated by subtracting the number of mol of substrate adsorbed during the dark test from the number of mol of substrate eliminated from solution at the end of the photocatalytic test. The $\alpha-\mathrm{Fe}_{2} \mathrm{O}_{3} @ \mathrm{COK}-12$ material showed a higher TON in both photodegradation of rhodamine $6 \mathrm{G}(\mathrm{TON}=76)$ and 1-adamantanol $(\mathrm{TON}=86)$ as compared to commercial $\alpha-\mathrm{Fe}_{2} \mathrm{O}_{3}$ nanopowder, achieving TON values of 8.3 and 55 for rhodamine $6 \mathrm{G}$ and 1-adamantanol, respectively. Importantly, the $\alpha-\mathrm{Fe}_{2} \mathrm{O}_{3} @ \mathrm{COK}-12$ catalyst could be reused for at least three cycles without significant inactivation. Several reasons may account for the improved photocatalytic activity of $\alpha-\mathrm{Fe}_{2}$ $\mathrm{O}_{3}$ @COK-12 over the bulk $\alpha-\mathrm{Fe}_{2} \mathrm{O}_{3}$ reference catalyst as demonstrated in this study. First, the COK-12 acting as a host offers excellent homogeneous dispersion of $\alpha-\mathrm{Fe}_{2} \mathrm{O}_{3}$ nanorods for high accessibility to the substrate while preventing the aggregation of particles that limits the performance of the commercial $\alpha-\mathrm{Fe}_{2} \mathrm{O}_{3}$ particles. ${ }^{85}$ Moreover, the large surface area and porous structure of COK-12 as a host also provide more abundant active sites for the photodegradation of the organic molecules. ${ }^{86}$ The highaspect-ratio of $\alpha-\mathrm{Fe}_{2} \mathrm{O}_{3}$ nanorods provided sufficient thickness of the absorber layer to maximize visible light absorption for improving the electron-hole pair separation. ${ }^{49,87}$

\section{Conclusions}

We demonstrated the first successful fabrication of hematite iron oxide nanorods inside the mesochannels of COK-12 platelets. High resolution HAADF-STEM imaging enables direct visualization of the iron oxide nanorods distributed along the hexagonal arrays of mesopores, providing detailed insight into the size, shape and distribution of the nanorods at its nanometer dimension. Three-dimensional visualization of single iron oxide nanorod allocation in individual mesochannels was achieved by electron tomography. Excellent dispersion of the iron oxide nanorods greatly improved the photocatalytic performance, as evidenced from the enhanced photocatalytic activity of the $\alpha-\mathrm{Fe}_{2} \mathrm{O}_{3}$ @COK-12 under visible light achieving higher TONs as compared to the commercial $\alpha-\mathrm{Fe}_{2} \mathrm{O}_{3}$ aggregated nanocatalyst. The combination of HAADF-STEM imaging and electron tomography have successfully shed light on the structure-performance relationship in this complex nanostructured material. This hybrid composite material could be also useful for other emerging advanced applications such as visible light triggered drug release and water splitting.

\section{Acknowledgements}

L. H. W. and S. T. thank the FWO-Vlaanderen for a postdoctoral research fellowship $(12 \mathrm{M} 1415 \mathrm{~N})$ and under contract number G004613N. J. A. M. gratefully acknowledge financial supports from Flemish Government (Long-term structural fundingMethusalem). Collaboration among universities was supported by the Belgian Government (IAP-PAI network).

\section{Notes and references}

1 C. T. Kresge, M. E. Leonowicz, W. J. Roth, J. C. Vartuli and J. S. Beck, Nature, 1992, 359, 710. 
2 J. S. Beck, J. C. Vartuli, W. J. Roth, M. E. Leonowicz, C. T. Kresge, K. D. Schmitt, C. T. D. Chu, D. H. Olson, E. W. Sheppard, S. B. McCullen, J. B. Higgins and J. L. Schlenker, J. Am. Chem. Soc., 1992, 114, 10834.

3 D. Zhao, J. Feng, Q. Huo, N. Melosh, G. H. Fredrickson, B. F. Chmelka and G. D. Stucky, Science, 1998, 279, 548.

4 H.-P. Lin and C.-Y. Mou, Acc. Chem. Res., 2002, 35, 927-935. 5 P. Yang, D. Zhao, B. F. Chmelka and G. D. Stucky, Chem. Mater., 1998, 10, 2033.

6 J. Wei, H. Wang, Y. Deng, Z. Sun, L. Shi, B. Tu, M. Luqman and D. Zhao, J. Am. Chem. Soc., 2011, 133, 20369.

7 J. Fan, C. Yu, J. Lei, Q. Zhang, T. Li, B. Tu, W. Zhou and D. Zhao, J. Am. Chem. Soc., 2005, 127, 10794.

8 H. Zhang, J. Sun, D. Ma, X. Bao, A. Klein-Hoffmann, G. Weinberg, D. Su and R. Schlögl, J. Am. Chem. Soc., 2004, 126, 7440.

9 L. Wang, T. Qi, Y. Zhang and J. Chu, Microporous Mesoporous Mater., 2006, 91, 156.

10 B. G. Trewyn, C. M. Whitman and V. S. Y. Lin, Nano Lett., 2004, 4, 2139.

11 J. Sun, H. Zhang, R. Tian, D. Ma, X. Bao, D. S. Su and H. Zou, Chem. Commun., 2006, 1322.

12 J.-S. Lee, S. H. Joo and R. Ryoo, J. Am. Chem. Soc., 2002, 124, 1156.

13 P. Verlooy, A. Aerts, O. Lebedev, G. van Tendeloo, C. Kirschhock and J. Martens, Chem. Commun., 2009, 28, 4287.

14 D. Zhao, J. Sun and Q. Li, Chem. Mater., 2000, 12, 275.

15 H. I. Lee, J. K. Kim, G. D. Stucky, Y. Shi, C. Pak and J. M. Kim, J. Mater. Chem., 2010, 20, 8483.

16 K. Kosuge, T. Sato, N. Kikukawa and M. Takemori, Chem. Mater., 2004, 16, 899.

17 S.-Y. Chen, C.-Y. Tang, W.-T. Chuang, J.-J. Lee, Y.-L. Tsai, J. C. C. Chan, C.-Y. Lin, Y.-C. Liu and S. Cheng, Chem. Mater., 2008, 20, 3906.

18 P. Linton and V. Alfredsson, Chem. Mater., 2008, 20, 2878.

19 A. Sayari, B.-H. Han and Y. Yang, J. Am. Chem. Soc., 2004, 126, 14348.

20 X. Ji, K. T. Lee, M. Monjauze and L. F. Nazar, Chem. Commun., 2008, 36, 4288.

21 J. Jammaer, T. S. van Erp, A. Aerts, C. E. A. Kirschhock and J. Martens, J. Am. Chem. Soc., 2011, 133, 13737.

22 J. Jammaer, A. Aerts, J. D'Haen, J. W. Seo and J. Martens, J. Mater. Chem., 2009, 19, 8290.

23 U. Ciesla and F. Schüth, Microporous Mesoporous Mater., 1999, 27, 131.

24 K. Moller and T. Bein, Chem. Mater., 1998, 10, 2950.

25 Y. Wang and F. Caruso, Chem. Mater., 2005, 17, 953.

26 J. E. Lee, N. Lee, H. Kim, J. Kim, S. H. Choi, J. H. Kim, T. Kim, I. C. Song, S. P. Park, W. K. Moon and T. Hyeon, J. Am. Chem. Soc., 2010, 132, 552.

27 W.-H. Zhang, J.-L. Shi, H.-R. Chen, Z.-L. Hua and D.-S. Yan, Chem. Mater., 2001, 13, 648.

28 C.-N. Yang, P.-H. Liu, Y.-F. Ho, C.-Y. Chiu and K. J. Chao, Chem. Mater., 2003, 15, 275-280.

29 H. Yang, Q. Lu, F. Gao, Q. Shi, Y. Yan, F. Zhang, S. Xie, B. Tu and D. Zhao, Adv. Funct. Mater., 2005, 15, 1377.
30 J. E. Lee, N. Lee, T. Kim, J. Kim and T. Hyeon, Acc. Chem. Res., 2011, 44, 893.

31 M. Vallet-Regí, F. Balas and D. Arcos, Angew. Chem., Int. Ed., 2007, 46, 7548.

32 Y. Zhao, B. G. Trewyn, I. I. Slowing and V. S.-Y. Lin, J. Am. Chem. Soc., 2009, 131, 8398.

33 J. Kim, J. E. Lee, J. Lee, J. H. Yu, B. C. Kim, K. An, Y. Hwang, C.-H. Shin, J.-G. Park, J. Kim and T. Hyeon, J. Am. Chem. Soc., 2006, 128, 688.

34 C.-G. Wu and T. Bein, Science, 1994, 264, 1757.

35 C.-G. Wu and T. Bein, Science, 1994, 266, 1013.

36 A. Taguchi and F. Schüth, Microporous Mesoporous Mater., 2005, 77, 1 .

37 M. M. Moghaddam, B. Pieber, T. Glasnov and C. O. Kappe, ChemSusChem, 2014, 7, 3122.

38 D. Cantillo, M. Baghbanzadeh and C. O. Kappe, Angew. Chem., Int. Ed., 2012, 51, 10190.

39 D. Obermayer, A. M. Balu, A. A. Romero, W. Goessler, R. Luque and C. O. Kappe, Green Chem., 2013, 15, 1530.

40 F. Jiao and H. Frei, Angew. Chem., Int. Ed., 2009, 48, 1841.

41 A. Corma, Chem. Rev., 1997, 97, 2373.

42 N. Insin, J. B. Tracy, H. Lee, J. P. Zimmer, R. M. Westervelt and M. G. Bawandi, ACS Nano, 2008, 2, 197.

43 S. Giri, B. G. Trewyn, M. P. Stellmaker and V. S.-Y. Lin, Angew. Chem., Int. Ed., 2005, 44, 5038.

44 S. Gandhi, S. Venkatesh, U. Sharma, N. R. Jagannathan, S. Sethuraman and U. M. Krishnan, J. Mater. Chem., 2011, 21, 15698.

45 Z. Teng, J. Li, F. Yan, R. Zhao and W. Yang, J. Mater. Chem., 2009, 19, 1811.

46 F. Martínez, G. Calleja, J. A. Melero and R. Molina, Appl. Catal., B, 2007, 70, 452.

47 Y. Sun, S. Walspurger, J.-P. Tessonnier, B. Louis and J. Sommer, Appl. Catal., A, 2006, 300, 1.

48 J. A. Melero, G. Calleja, F. Martínez, R. Molina and M. I. Pariente, Chem. Eng. J., 2007, 131, 245.

49 M. Ebaid, J.-H. Kang, S.-H. Lim, J.-S. Ha, J. K. Lee, Y.-H. Cho and S.-W. Ryu, Nano Energy, 2015, 12, 215.

50 P. A. Midgley and R. E. Dunin-Borkowski, Nat. Mater., 2009, 8, 271.

51 M. C. Scott, C.-C. Chen, M. Mecklenburg, C. Zhu, R. Xu, P. Ercius, U. Dahmen, B. C. Regan and J. Miao, Nature, 2012, 483, 444.

52 B. Goris, S. Bals, W. van den Broek, E. Carbó-Argibay, S. Gómez-Graña, L. M. Liz-Marzán and G. van Tendeloo, Nat. Mater., 2012, 11, 930.

53 S. Bals, M. Casavola, M. A. van Huis, S. van Aert, K. J. Batenburg, G. van Tendeloo and D. Vanmaekelbergh, Nano Lett., 2011, 11, 3420.

54 E. Biermans, L. Molina, K. J. Batenburg, S. Bals and G. van Tendeloo, Nano Lett., 2010, 10, 5014.

55 S. Bals, K. J. Batenburg, J. Verbeeck, J. Sijbers and G. van Tendeloo, Nano Lett., 2007, 7, 3669.

56 F. Leroux, M. Gysemans, S. Bals, K. J. Batenburg, J. Snauwaert, T. Verbiest, C. van Haesendonck and G. van Tendeloo, Adv. Mater., 2010, 22, 2193. 
57 E. P. W. Ward, T. J. V. Yates, F. José-Jesús, D. E. W. Vaughan and P. A. Midgley, J. Phys. Chem. C, 2007, 111, 11501.

58 A. Yurtsever, M. Weyland and D. A. Muller, Appl. Phys. Lett., 2006, 89, 151920.

59 G. Prieto, J. Zecĕvić, H. Friedrich, K. P. de Jong and P. E. de Jongh, Nat. Mater., 2013, 12, 34.

60 A. H. Janssen, C.-M. Yang, Y. Wang, F. Schüth, A. J. Koster and K. P. de Jong, J. Phys. Chem. B, 2003, 107, 10552.

61 A. J. Koster, U. Ziese, A. J. Verkleij, A. H. Janssen and K. P. de Jong, J. Phys. Chem. B, 2000, 104, 9368-9370.

62 O. Ersen, J. Werckmann, M. Houllé, M.-J. Ledoux and C. Pham-Huu, Nano Lett., 2007, 7, 1898.

63 I. Florea, A. Demortière, C. Petit, H. Bulou, C. Hirlimann and O. Ersen, ACS Nano, 2012, 6, 2574.

64 H. Friedrich, J. R. A. Sietsma, P. E. de Jongh, A. J. Verkleij and K. P. de Jong, J. Am. Chem. Soc., 2007, 129, 10249.

65 I. Florea, M. Houllé, O. Ersen, L. Roiban, A. Deneuve, I. Janowska, P. Nguyen, C. Pham and C. Pham-Huu, J. Phys. Chem. C, 2009, 113, 17711.

66 C. J. Gommes, H. Friedrich, M. Wolters, P. E. de Jongh and K. P. de Jong, Chem. Mater., 2009, 21, 1311.

67 H. Friedrich, S. Guo, P. E. de Jongh, X. Pan, X. Bao and K. P. de Jong, ChemSusChem, 2011, 4, 957.

68 J. Zecĕvić, C. J. Gommes, H. Friedrich, P. E. de Jongh and K. P. de Jong, Angew. Chem., Int. Ed., 2012, 51, 4213.

69 S. Bals, K. J. Batenburg, D. Liang, O. Lebedev, G. van Tendeloo, A. Aerts, J. A. Martens and C. E. A. Kirschhock, J. Am. Chem. Soc., 2009, 131, 4769.

70 S. Turner, O. L. Lebedev, F. Schröder, D. Esken, R. A. Fischer and G. van Tendeloo, Chem. Mater., 2008, 20, 5622.

71 H. Friedrich, P. E. de Jongh, A. J. Verkleij and K. P. de Jong, Chem. Rev., 2009, 109, 1613.
72 J. Zecĕvić, A. M. J. van der Eerden, P. E. de Jongh and K. P. de Jong, ACS Nano, 2013, 7, 3698.

73 H. Yang, F. Gao, Q. Shi, Y. Yan, F. Zhang, S. Xie, B. Tu and D. Zhao, Adv. Funct. Mater., 2005, 15, 1377.

74 D. M. Hess, R. R. Naik, C. Rinaldi, M. M. Tomczak and J. J. Watkins, Chem. Mater., 2009, 21, 2125.

75 M. Fröba, R. Köhn and G. Bouffaud, Chem. Mater., 1999, 11, 2858.

76 R. Köhn, D. Paneva, M. Dimitrov, T. Tsoncheva, I. Mitov, C. Minchev and M. Fröba, Microporous Mesoporous Mater., 2003, 63, 125.

77 T. Suteewong, H. Sai, J. Lee, M. Bradbury, T. Hyeon, S. M. Gruner and U. Wiesner, J. Mater. Chem., 2010, 20, 7807.

78 F. Gao, Q. Lu, X. Liu, Y. Yan and D. Zhao, Nano Lett., 2001, 1, 743.

79 P. Gilbert, J. Theor. Biol., 1972, 36, 105.

80 T. Abe, Y. Tachibana, T. Uematsu and M. Iwamoto, J. Chem. Soc., Chem. Commun., 1995, 1617.

81 W. Wu, C. Jiang and V. A. L. Roy, Nanoscale, 2015, 7, 38.

82 G. K. Pradhan, D. K. Padhi and K. M. Parida, ACS Appl. Mater. Interfaces, 2013, 5, 9101.

83 G. K. Pradhan and K. M. Parida, ACS Appl. Mater. Interfaces, 2011, 3, 317.

84 L. H. Wee, N. Janssens, J. Vercammen, L. Tamaraschi, L. C. J. Thomassen and J. A. Martens, J. Mater. Chem. A, 2015, 3, 2258.

85 B. C. Ma, S. Ghasimi, K. Landfester, F. Vilela and K. A. I. Zhang, J. Mater. Chem. A, 2015, 3, 16064.

86 B. Y. Yu and S.-Y. Kwak, J. Mater. Chem., 2012, 22, 8352.

87 W. U. Huynh, J. J. Dittmer and A. P. Alivisatos, Science, 2002, 295, 2425. 